\title{
Mesenchymal stromal cell therapy improves myocardial function after severe ischaemic heart failure
}

Intramyocardial injection of mesenchymal stromal cells (MSCs) has shown beneficial effects in small studies of patients with chronic ischaemic heart disease and heart failure (HF). Results from the MSC-HF trial now show improvements in left ventricular (LV) systolic function in patients with ischaemic HF who received MSCs by intramyocardial injection.

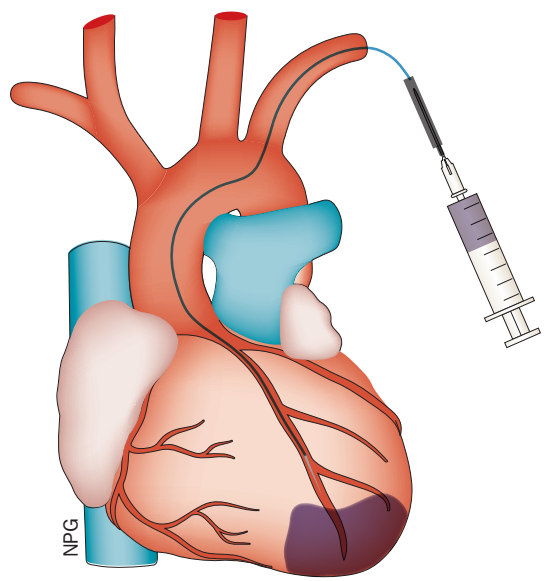

Patients with severe ischaemic HF, a LV ejection fraction (LVEF) $<45 \%$, who were in NYHA class II-III, and had no other treatment options available were randomly allocated, in a 2:1 ratio, to receive an intramyocardial injection of autologous MSCs $(n=40)$ or placebo $(n=20)$, respectively, in a double-blinded procedure. The primary end point of change in LV end-systolic volume (LVESV) was measured using MRI or CT at 6-month follow-up.

LVESV was reduced in patients who received MSCs $(-7.6 \mathrm{ml}, 95 \% \mathrm{CI}-11.8 \mathrm{ml}$ to $-3.4 \mathrm{ml}, P=0.001)$, but tended to increase in those who received placebo $(5.4 \mathrm{ml}, 95 \% \mathrm{CI}$ $-0.4 \mathrm{ml}$ to $11.2 \mathrm{ml}, P=0.07$ ); the difference in LVESV between the two groups was $13.0 \mathrm{ml}$ (95\% CI 5.9-20.1 ml). Patients in the MSC group also had improved LVEF (6.2\%; $P<0.0001)$, stroke volume (18.4 ml; $P<0.0001)$, and myocardial mass (5.7 g; $P=0.001)$ compared with patients in the placebo group.
"This cell type has shown promising results in clinical trials, and in animal comparison studies MSCs have been superior to mononuclear cells from bone marrow," adds Anders Mathiasen, the corresponding author of this study. Two multicentre trials are currently being planned by the investigators of the MSC-HF study to support this therapeutic approach to improve myocardial regeneration. "In both trials we will use allogeneic MSCs from healthy donors. The cells will be prepared and frozen at Copenhagen University Hospital Rigshospitalet, Denmark and will be distributed to the other centres after patients are included," adds Mathiasen.

\section{João H. Duarte}

Original article Mathiasen, A. B. et al. Bone marrowderived mesenchymal stromal cell treatment in patients with severe ischaemic heart failure: a randomized placebocontrolled trial (MSC-HF trial). Eur. Heart J. doi:10.1093/ eurheartj/ehv136 